Relations industrielles

Industrial Relations

\title{
Work Sharing: Case Studies, by Maureen McCarthy and Gail S. Rosenberg, Kalamazoo, Michigan, W.E. Upjohn Institute for Employment Research, 1981, 277 pp., ISBN 0-911558-87-X.
}

\section{Alain Vinet}

Volume 37, numéro 4, 1982

URI : https://id.erudit.org/iderudit/029317ar

DOI : https://doi.org/10.7202/029317ar

Aller au sommaire du numéro

Éditeur(s)

Département des relations industrielles de l'Université Laval

ISSN

0034-379X (imprimé)

1703-8138 (numérique)

Découvrir la revue

Citer ce compte rendu

Vinet, A. (1982). Compte rendu de [Work Sharing: Case Studies, by Maureen McCarthy and Gail S. Rosenberg, Kalamazoo, Michigan, W.E. Upjohn Institute for Employment Research, 1981, 277 pp., ISBN 0-911558-87-X.] Relations industrielles / Industrial Relations, 37(4), 971-971.

https://doi.org/10.7202/029317ar

Tous droits réservés @ C Département des relations industrielles de l'Universite Laval, 1982
Ce document est protégé par la loi sur le droit d'auteur. L'utilisation des services d'Érudit (y compris la reproduction) est assujettie à sa politique d'utilisation que vous pouvez consulter en ligne.

https://apropos.erudit.org/fr/usagers/politique-dutilisation/ 
Work Sharing: Case Studies, by Maureen McCarthy and Gail S. Rosenberg, Kalamazoo, Michigan, W.E. Upjohn Institute for Employment Research, 1981, 277 pp., ISBN 0-911558-87-X.

Ce livre décrit une variété de situations apparentées au travail partagé (Work Sharing). Les exemples étudiés proviennent des États-Unis et couvrent des situations aussi diverses que la rotation des employés, le partage des emplois, le congé sans solde (durée accrue des vacances), la retraite anticipée, etc. Les expériences qui ont permis de préserver des emplois ou d'en créer de nouveaux sont particulièrement mises en évidence.

L'objectif poursuivi par les auteurs est d'offrir aux employeurs du secteur privé des informations concrètes et pratiques afin de leur permettre d'apprécier la viabilité de ces expériences et de susciter des innovations semblables dans leur entreprise. Afin d'atteindre cet objectif, les auteurs ont adopté la formule des études de cas. Chaque chapitre de ce livre débute par une description des caractéristiques communes aux cas qui y sont regroupés; très tôt cependant, l'analyse et le commentaire font place aux histoires de cas.

Plus de 36 expériences sont décrites en profondeur dans ce volume. La plupart d'entre elles proviennent du secteur privé bien que quelques initiatives du secteur public soient également présentées. Dans un cas sur trois les employés ne sont pas syndiqués.

Les études de cas retenues dans ce livre sont regroupées sous trois rubriques générales: réduction temporaire des heures de travail, réduction permanente des heures de travail, horaires flexibles. Un chapitre est consacré à chacun de ces types d'aménagement du temps de travail. La formule de présentation est identique d'un chapitre à l'autre: au début du chapitre les auteurs définissent les concepts et catégories utilisés, présentent un aperçu historique des développements survenus dans le domaine et décrivent les plus récentes innovations législatives en la matière. Les avantages et les inconvénients de chacune des formes d'aménagement du temps de tra- vail y sont également discutés. Par la suite, les études de cas complètent l'information transmise dans la partie théorique.

Alain VINET

Université Laval

La langue et le revenu du travail à Montréal, par Jac-André Boulet, Ottawa, Ministère des Approvisionnement et Services Canada, Une étude préparée pour le Conseil économique du Canada, 1980, 135 pp., ISBN 0-660-90515-9.

Cette étude vise à déterminer les causes des disparités de revenu entre les francophones et les anglophones de la zone métropolitaine de Montréal à partir des recensements de 1961, de 1971 et de données fournies par le professeur Paul Bernard et Jean Renaud, du département de Sociologie de l'Université de Montréal pour l'année 1977. Elle se divise en cinq chapitres: 1- Les paramètres de l'étude, 2- Panorama théorique, 3- L'utilité de l'approche conventionnelle, 4- La distribution des disparités linguistiques entre francophones et anglophones en 1970.

Dans le premier chapitre, l'auteur explique pourquoi il choisit de faire son analyse selon la langue au lieu de l'ethnicité. La raison est que les écarts de revenus entre les divers groupes linguistiques croisés avec l'origine ethnique sont plus importants selon la langue que selon l'ethnicité. Néanmoins, au cours de son analyse, il ne revient à peu près pas sur les groupes qui s'opposent le plus à ce point de vue. D'ailleurs, la majeure partie de sa discussion consiste tout simplement à comparer entre eux les francophones et les anglophones parce que, dit-il, «L'intérêt de l'analyse n'en souffrira pas (...) puisqu'il est bien connu que ce sont d'abord les disparités de revenus entre francophones et anglophones qui sont au centre des préoccupations.» Le premier chapitre perd ainsi beaucoup de son sens et de son utilité. L'auteur aurait pu s'en passer. Les disparités de revenus peuvent être analysées tant du point de vue linguistique qu'ethnique. Chacun de ces points de vue présente ses avantages et ses limites qu'il 